\title{
EFFECTIVENESS OF BIOFILTER MADE FROM PLASTIC WASTE TO DECREASE BOD, COD AND AMMONIA OF HOSPITAL WASTEWATER
}

\author{
I Putu Sri Juniarta ${ }^{1 *)}$, I Wayan Budiarsa Suyasa ${ }^{2)}$, IGBSila Dharma ${ }^{3)}$ \\ ${ }^{1)}$ Dinas Lingkungan Hidup dan Pertanahan Kabupaten Klungkung \\ ${ }^{2)}$ Fakultas Matematika dan Ilmu Pengetahuan Alam Universitas Udayana \\ 3) Fakultas Kelautan Universitas Udayana \\ *Email: juniartamc98@yahoo.com
}

\begin{abstract}
This study aims to determine the influence of biofilter made from plastic waste to decrease BOD, COD and Ammonia content and to determine the efficacy of its use to decrease BOD, COD and Ammonia content from the hospital's wastewater.This study utilized aerobic biofilter processing through a batch system. Variables used in this research are wastewater processing through biofilter media made from plastic waste and processing without biofilter media, with 36 hours retention time. The parameters are BOD, COD and Ammonia content. From the statistical analysis, the use of biofilter media made from plastic waste gives a significant effect to decrease BOD and Ammonia content but made no significant effect to decrease COD. Plastic waste biofilter processing system is very effective to decrease BOD (84,85\%), less effective to decrease COD (31,73\%) but effective enough to decrease ammonia $(50,60 \%)$, meanwhile, the standard quality of plastic waste biofilter processing system is effective to reduce BOD and COD content but not effective to reduce the ammonia content after 36 hours of processing time.Further research is needed to study the efficacy of biofilter media made from other type of plastic waste. Moreover, a combination of anaerob-aerobic biofilter processing is required to improve processing efficacy.
\end{abstract}

Keywords: biofilter,plastic waste, hospital wastewater, BOD, COD, ammonia.

\section{PENDAHULUAN}

Penggunaan plastik memberikan banyak manfaat bagi masyarakat, penggunaan plastik dilakukan hampir pada seluruh kegiatan masyarakat, namun penggunaan yang tidak terkontrol nantinya akan menimbulkan dampak negatif bagi pencemaran lingkungan. Menurut Dewi (2009), sampah yang diproduksi di Jakarta khususnya sebesar 6000 ton per hari dengan 70 hingga 80 persen dari sampah tersebut tergolong sampah anorganik, dan proporsi ini terus meningkat. Sampah plastik tidak hanya menjadi masalah di kalangan masyarakat umum tetapi juga menjadi masalah bagi perindustrian di Indonesia.

Salah satu cara untuk mendegradasi limbah domestik yang ramah lingkungan adalah dengan cara biologis dengan sistem biofilter aerob. Pada biofilter aerob, air limbah yang diolah akan mengalami kontak dengan mikroorganisme yang tersuspensi dalam air maupun yang menempel pada permukaan media (biofilm). Biofilter aerob ini memiliki kelebihan diantaranya pengoperasiannya mudah, lumpur yang dihasilkan relatif sedikit (dibanding proses lumpur aktif), dapat digunakan untuk mengolah limbah dengan konsentrasi tinggi atau rendah serta tahan terhadap fluktuasi jumlah limbah, konsentrasi dan suhu (Herlambang dan Nusa, 2001).

Air limbah rumah sakit adalah semua limbah cair yang berasal dari kegiatan-kegiatan rumah sakit antara lain dari kegiatan pencucian atau laundry, dapur, floor drain, laboratorium, toilet, wastafel, ruang perawatan, UGD, ruang bedah, kebidanan dan lain-lain (Kementerian Kesehatan RI, 2011). Air limbah rumah sakit umumnya mempunyai komposisi yang hampir sama dengan limbah rumah tangga atau domestik. Perbedaannya adalah adanya kandungan mikroorganisme, bahan kimia beracun dan bahan radioaktif yang terdapat limbah rumah sakit.

Dengan melihat berbagai penelitian mengenai sistem biofilter aerob, permasalahan akibat sampah plastik dan limbah domestik dari kegiatan rumah sakit, penulis mencoba merancang penelitian untuk mengetahui tingkat efektivitas sistem biofilter aerob dengan menggunakan media biofilter berbahan sampah plastik sehingga diharapkan mampu menurunkan kadar BOD, COD dan Amonia pada limbah cair rumah sakit. Tujuandaripenelitianini adalah untuk (1) untuk menentukan pengaruh penggunaan biofilter berbahan sampah plastik dalam menurunkan kadar BOD, COD, amonia limbah cair rumah sakit. (2) untuk menentukan tingkat efektivitas penurunan kadar BOD, COD, amonia limbah cair rumah sakit menggunakan biofilter berbahan sampah plastik.

\section{METODOLOGI}

\subsection{Lokasi dan Waktu Penelitian}

Lokasi pengambilan sampel air limbah domestik dilakukan di saluran influent Instalasi Pengolahan 
Air Limbah Rumah Sakit Umum Daerah Kabupaten. Pengoperasian sistem biofilter aerob dilakukan di Laboratorium Lingkungan Dinas Lingkungan Hidup dan Pertanahan Kabupaten Klungkung. Waktu penelitian dilakukan pada bulan Januari 2017 sampai dengan Maret 2017.

\subsection{Prosedur Penelitian}

Prosedur penelitian yang dilakukan yaitu pengumpulan dan pemilahan sampah plastik, pencucian sampah plastik, pembuatan media filter dari sampah plastik, penumbuhan biofilm pada media filter, pengambilan sampel air limbah, pengolahan dengan sistem biofilter aerob, pengukuran parameter, dan analisis data.

\subsubsection{Pengumpulan dan Pemilihan Sampah Plastik}

Sampah plastik yang dikumpulkan pada penelitian ini dibatasi kepada dua jenis sampah plastik yaitu sampah botol air mineral ukuran 600 ml dan sampah sisa pembungkus snack. Pengumpulan sampah plastik dilakukan dari berbagai sumber secara acak. Sampah plastik diperoleh dari tempat sampah kantin, perkantoran, sekolah, TPS, bank sampah dan TPST.

Kemudian dilakukan pemilihan terhadap sampah plastik. Pemilihan terhadap sampah plastik yang akan digunakan bertujuan untuk mendapatkan sampah plastik yang masih bagus, lebih tebal dan kuat sehingga dapat digunakan sebagai bahan media biofilter yang dapat bertahan dalam jangka waktu yang lama.

\subsubsection{Pencucian Sampah Plastik}

Sebelum sampah plastik digunakan sebagai media biofilter terlebih dahulu dilakukan pencucian terhadap sampah tersebut. Hal ini bertujuan untuk mengurangi berbagai kotoran yang menempel sehingga tidak mempengaruhi proses pada sistem biofilter. Setelah dicuci kemudian sampah-sampah tersebut dikeringkan.

\subsubsection{Pembuatan Media Filter dari Sampah Plastik}

Pembuatan media filter diawali dengan melubangi botol air aqua ukuran $600 \mathrm{ml}$ pada bagian bawah, samping, dan atas. Kemudian kedalam masing-masing botol air mineral dimasukkan sampah dari pembungkus snack sehingga berat masing-masing botol menjadi 25 gram. Botol air mineral yang sudah berisi sampah kantong plastik kemudian dirangkai sedemikian rupa.

Media filter dari sampah plastik tersebut kemudian digunakan sebagai media filter untuk mengolah limbah.

\subsubsection{Penumbuhan Biofilm pada Media Filter}

Penumbuhan lapisan biofilm pada media filter dilakukan dengan merendam media filter tersebut pada bak yang berisi 80 liter air limbah outlet RSUD Klungkung yang sudah ditambah 50 gram sedimen lumpur dari bak ekualisasi IPAL RSUD Klungkung kemudian ditambahkan nutrien hara yaitu pupuk urea 10,71 gram, pupuk TSP 2,209 gram dan glukosa 125 gram sampai terbentuknya lapisan biofilm pada seluruh media filter. Penumbuhan biofilm pada media filter dilakukan selama 30 hari (Herlambang dan Marsidi, 2003).

Apabila biofilm sudah tumbuh dan sudah siap untuk mengolah air limbah maka media harus dibilas terlebih dahulu dengan air bersih. Pembilasan dilakukan sebanyak 2 kali untuk mengurangi sisa nutrien yang menempel di media.Kemudian media dimasukan kedalam reaktor aerob, yang selanjutnya dialiri air limbah domestik rumah sakit.

\subsubsection{Pengambilan Sampel Air Limbah}

Metoda sampling yang digunakan adalah non random sampling atau purposive. Pengambilan sampel air limbah dilakukan pada saluran outlet bak ekualisasi Instalasi Pengolahan Air Limbah Rumah Sakit Umum Daerah Kabupaten Klungkung. Pengambilan sampel dilakukan mulai pukul 10.00 pagi sampai dengan jam 11.00 Wita.

\subsubsection{Pengolahan Dengan Sistem Biofilter Aerob}

Reaktor aerob dibuat dari bak dengan ukuran $50 \mathrm{~cm}$ x $50 \mathrm{~cm}$ dan tinggi $50 \mathrm{~cm}$. Kapasitas air limbah yang diolah adalah 75 liter. Alat biofilter aerob ini disiapkan sebanyak dua buah. Skema reaktor aerob yang digunakan dalam penelitian seperti terlihat pada Gambar 1.

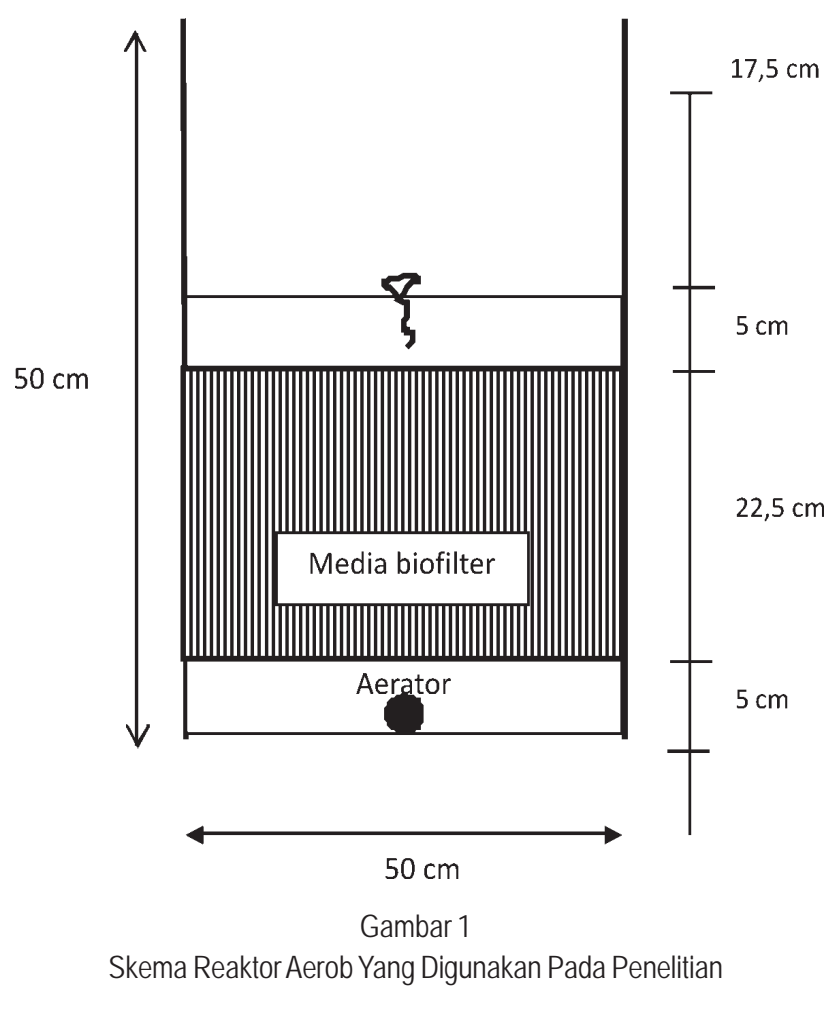




\subsubsection{Penentuan Pengaruh Penggunaan Biofilter dan Efektivitas Penurunan Parameter}

Penentuan pengaruh penggunaan biofilter berbahan sampah plastik dan tingkat efektivitas penurunan parameter dilakukan dengan menggunakan dua (2) buah bak. Pada kedua bak masing-masing dipasang aerator untuk menyuplai oksigen saat proses pengolahan. Kedalam dua bak kaca masing-masing diisi:

Bak 1: Dengan media biofilter berbahan sampah plastik (R1)

Bak 2： Tanpa media biofilter (R2)

Masing-masing bak dialirkan sebanyak 75 liter air limbah cair domestik rumah sakit.Air limbah pada semua reaktor pengolahan selanjutnya diberikan waktu tinggal pengolahan selama 36 jam. Setiap selang waktu pengolahan, dilakukan pengambilan sampel air untuk analisis kadar COD, BOD, dan amonia pada air limbah. Pengamatan sampel air dilakukan dengan mengukur nilai $\mathrm{pH}$, suhu dan kadar oksigen terlarut (DO). Dari pengukuran kadar BOD, COD, dan amonia dilakukan perhitungan mengenai tingkat efektivitas sistem biofilter aerob dalam menurunkan kadar BOD, COD, dan amonia sesuai baku mutu yang ditetapkan. Untuk pengukuran kadar $\mathrm{pH}$, suhu dan DO dijadikan sebagai parameter penunjang dalam menentukan efektivitas penurunan kadar BOD, COD, dan amonia dengan biofilter aerob.

\subsection{Prosedur Analisis}

Untuk mengetahui tingkat efektivitas sistem pengolahan dengan biofilter aerob dilakukan dengan cara rekapitulasi data hasil pemeriksaan laboratorium terhadap keadaan awal dan akhir kadar BOD, COD dan Amonia pada air limbah. Data yang diperoleh dibuat grafik untuk kemudian dibandingkan dengan baku mutu air limbah domestik berdasarkan Peraturan Gubernur Bali

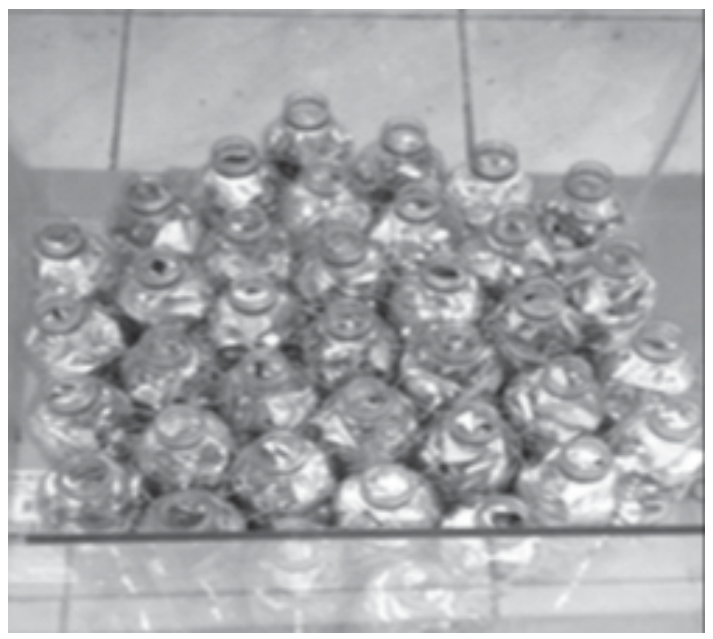

Gambar 3.

Setelah penumbuhan 30 hari
No.16 Tahun 2016. Rumus \% efektivitas yaitu:

$$
\% \text { efektivitas }=\frac{A-B}{A} \times 100 \%
$$

Keterangan :

A = kadar parameter awal.

$\mathrm{B}=$ kadar parameter akhir.

Selain itu digunakan analisis kovarians (Anakova) untuk menentukan ada tidaknya pengaruh penggunaan media biofilter terhadap penurunan kadar BOD, COD dan Amonia limbah cair rumah sakit selama proses pengolahan.

\section{HASIL DAN PEMBAHASAN}

\subsection{Penumbuhan Biofilm}

Penumbuhan biofilm dilakukan selama 30 hari karena menurut Herlambang dan Marsidi (2003) penumbuhan biofilm pada media plastik dilakukan selama 4-5 minggu sampai dengan tumbuhnya lendir pada permukaa media. Penelitian yang dilakukan oleh Wardhani et al. (2014) melakukan penumbuhan biofilm selama 30 hari pada media biofilter jaring ikan dan bioball. Selama proses penumbuhan biofilm dilakukan pengamatan visual untuk mengetahui adanya pertumbuhan biofilm selama waktu yang ditentukan. Pada penelitian ini tidak dilakukan pengukuran konsentrasi mikroorganisme selama proses penumbuhan. Perkiraan kuantitatif dan kualitatif konsentrasi mikroorganisme biofilm adalah tugas yang sangat sulit (Sudarno,2012)dan membutuhkan metoda biologi molekuler.

Perkembangan pertumbuhan bakteri dapat diamati dengan menghitung berat massa dari bakteri, aktifitas metabolisme dan dengan cara menghitung sel nya. Pengamatan ini akan mudah dalam kultur bakteri tersuspensi tetapi akan jauh lebih sulit bagi bakteri yang membentuk biofilm. Pengambilan bakteri pada kultur melekat akan sulit dan komplek, khususnya pada saat fase pertama dari

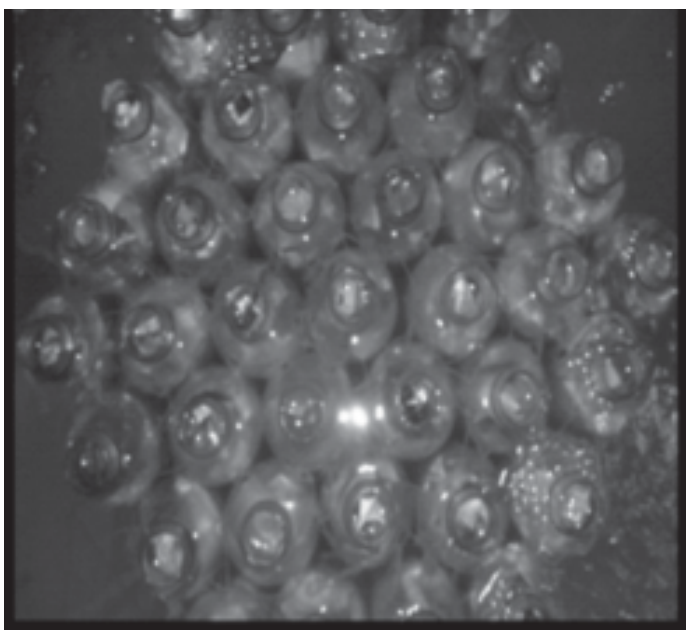

Gambar 2.

Sebelum penumbuhan 
pelekatan di media. Biofilm sangat tipis dan tidak terdistribusi merata serta berada dalam pori subtratum. Selain itu perkembangan biofilm tidak hanya proses perkembangbiakan dan kematian, melainkan ada proses detachment yang juga berperan signifikan dalam perkembangan biofilm (Sudarno,2012).

Dalam proses penumbuhan biofilm juga dilakukan analisis nilai $\mathrm{pH}$ dan $\mathrm{DO}$ untuk mengetahui keterkaitan kedua parameter tersebut selama proses pembibitan. Hasil analisis $\mathrm{pH}$ selama proses pembibitan ditunjukan pada gambar 5.2. Nilai $\mathrm{pH}$ selama proses penumbuhan biofilm berada pada rentang 7,51 - 8,48. pH (derajat keasaman) berpengaruh terhadap kehidupan mikroorganisme air. Pada proses penumbuhan biofilm cenderung terjadi kenaikan nilai $\mathrm{pH}$ seiring waktu pembibitan. Kondisi ini disebabkan karena terjadi proses penguraian yang terjadi oleh mikroorganisme terhadap nutrien yang diberikan seperti pupuk Urea, TSP dan Glukosa. Peningkatan nilai pH disebabkan karena penambahan nutrien yang bersifat basa (Wahyuni, 2014)

DO (oksigen terlarut) juga menjadi salah satu faktor penting yang mempengaruhi proses pembibitan biofilm. Mikroorganisme aerob memerlukan oksigen untuk menguraikan bahanbahan organik sebagai sumber energi. Bakteri nitrifikasi yang tumbuh didalam biofilm memerlukan DO $>1 \mathrm{mg} / \mathrm{l}$ sehingga proses berjalan dengan baik (Kementerian Kesehatan RI, 2011).

Berdasarkan nilai analisis kadar DO selama proses penumbuhan biofilm pada hari ke-0 sampai hari ke-7 terjadi kenaikan kadar oksigen terlarut, kemudian terjadi penurunan kadar oksigen terlarut dari hari ke-8 sampai hari ke-30. Hal ini disebabkan karena pada awal penumbuhan biofilm penggunaan oksigen sedikit karena konsentrasi mikroorganisme masih rendah sehingga oksigen terlarut cenderung naik akibat proses aerasi. Peningkatan kadar oksigen terlarut disebabkan oleh proses injeksi udara kedalam reaktor. Dengan adanya injeksi udara ini terjadi kontak antara gelembung udara dan air yang akan diolah dapat terjadi (Kementerian Kesehatan RI, 2011). Penggunaan oksigen semakin meningkat seiring dengan pertumbuhan mikroorganisme di media biofilm, sehingga menyebabkan terjadinya penurunan kadar oksigen terlarut. Penurunan kadar oksigen terlarut disebabkan akibat pemakaian oksigen oleh mikroorganisme untuk proses respirasi (Effendi, 2003). Mikroorganisme membutuhkan oksigen didalam menguraikan nutrien dan bahan organik selama proses pembibitan maupun pengolahan limbah secara aerob (Wahyuni, 2014).

\subsection{Pengaruh Penggunaan Biofilter Berbahan Sampah Plastik dalam Menurunkan Kadar BOD, COD dan Amonia}

Hasil pengukuran kadar BOD selama 36 jam pengolahan baik pada R1 (menggunakan media biofilter berbahan sampah plastik) dan R2 (tanpa media) dapat dilihat pada Gambar 4. Gambar 4 dapat dilihat trendpenurunan kadar BOD dimana pada awal pengolahan limbah cair rumah sakit mengandung kadar BOD sebesar 82,37 mg/L. Setelah melalui proses pengolahan pada reaktor dengan media biofilter berbahan sampah plastik selama 6 , 12, 18, 24, 30 dan 36 jam kadar BOD menjadi 73,77 $\mathrm{mg} / \mathrm{L}, 51,90 \mathrm{mg} / \mathrm{L}, 37,39 \mathrm{mg} / \mathrm{L}, 25,10 \mathrm{mg} / \mathrm{L}, 19,85$ $\mathrm{mg} / \mathrm{L}$ dan $11,66 \mathrm{mg} / \mathrm{L}$, sedangkan pada R2 pada awal pengolahan limbah cair rumah sakit mengandung kadar BOD sebesar 83,77 mg/L menjadi80,16 mg/L, $76,85 \mathrm{mg} / \mathrm{L}, 75,25 \mathrm{mg} / \mathrm{L}, 69,95 \mathrm{mg} / \mathrm{L}, 63,49 \mathrm{mg} / \mathrm{L}$ dan $60,63 \mathrm{mg} / \mathrm{L}$.

Gambar 4 dapat dilihat perbandingan penurunan kadar BOD pada R1 maupun R2 selama 36 jam proses pengolahan. Dari gambar tersebut dapat dilihat penurunan kadar BOD dengan perlakuan R1 memberikan hasil pengolahan akhir lebih baik dibanding dengan tanpa media biofilter. Gambar 4 dapat dilihat R1 mampu menurunkan kadar BOD dibawah baku mutu yang ditentukan, sedangkan R2 belum mampu menurunkan kadar BOD sampai baku mutu yang ditentukan.

Hasil pengukuran kadar COD selama 36 jam dapat dilihat pada Gambar 5. Pengukuran dilakukan pada jam ke-0, ke-6, ke-12, ke-18, ke-24, ke 30 dan ke-36. Pada R1 terjadi penurunan kadar COD yaitu dari $113,07 \mathrm{mg} / \mathrm{L}$ menjadi $77,19 \mathrm{mg} / \mathrm{L}$, sedangkan pada R2 terjadi penurunan kadar COD dari 105,87 $\mathrm{mg} / \mathrm{L}$ menjadi $87,61 \mathrm{mg} / \mathrm{L}$.

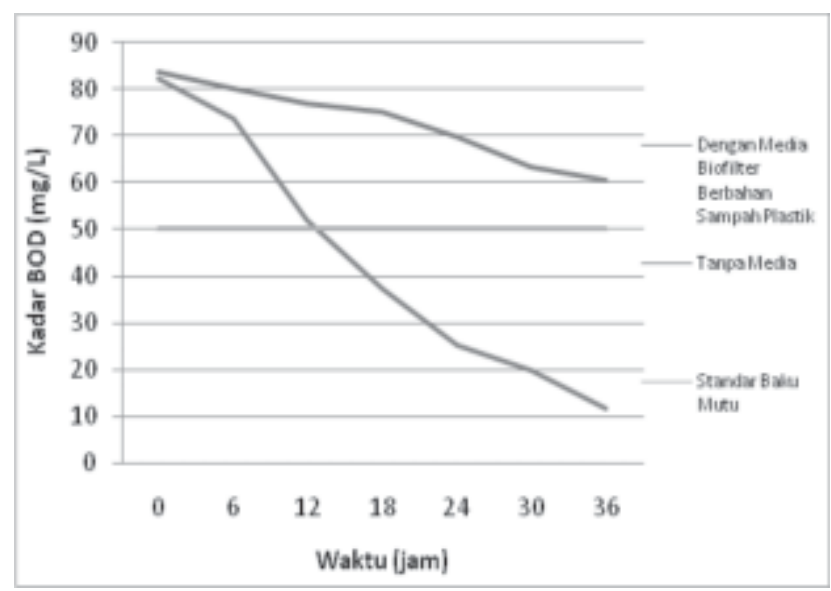

Gambar 4

Penurunan Kadar BOD Pada Masing-masing Perlakuan Selama 36 Jam Pengolahan 
Gambar 5 dapat dilihat penurunan kadar COD dengan perlakuan $\mathrm{R} 1$ memberikan hasil pengolahan akhir lebih baik dibanding dengan tanpa media biofilter. Gambar 5 dapat dilihat R1 mampu menurunkan kadar COD dibawah baku mutu yang ditentukan, sedangkan R2 belum mampu menurunkan kadar COD sampai baku mutu yang ditentukan.

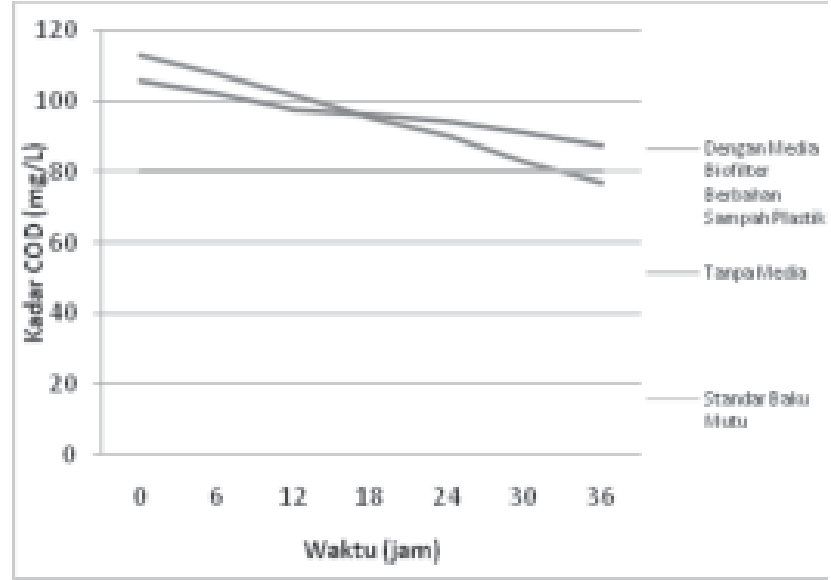

Gambar 5

Penurunan Kadar COD pada masing-masing perlakuan selama 36 jam pengolahan

Hasil pengukuran kadar Amonia selama 36 jam pengolahan dapat dilihat pada Gambar 6. Pengukuran dilakukan pada jam ke-0, ke-6, ke-12, ke-18, ke-24, ke 30 dan ke-36. Pada R1 terjadi penurunan kadar Amonia yaitu dari 26,44 mg/L menjadi 13,06 $\mathrm{mg} / \mathrm{L}$, sedangkan pada R2 terjadi penurunan kadar COD dari 27,65 mg/L menjadi 18,53 mg/L.

Gambar 6 dapat dapat dilihat penurunan kadar Amonia dengan perlakuan R1 memberikan hasil pengolahan akhir lebih baik dibanding dengan tanpa media biofilter.Gambar6 dapat dilihat perlakuan R1 dan R2 belum mampu menurunkan kadar Amonia sampai baku mutu yang ditentukan.

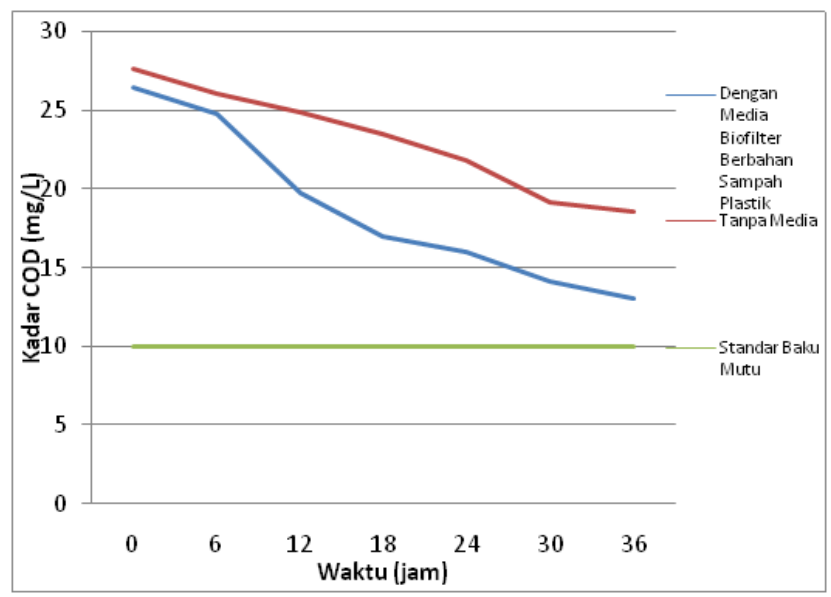

Gambar 6

Penurunan Kadar Amonia pada masing-masing perlakuan selama 36 jam pengolahan
Untuk mengetahui pengaruh penggunaan biofilter berbahan sampah plastik dilakukan dengan menggunakan dua jenis perlakuan untuk mengolah limbah cair domestik rumah sakit selama 36 jam pengolahan. Air limbah yang diambil adalah air limbah yang berasal dari outlet bak ekualisasi RSUD Klungkung, dimana limbah sudah mengalami proses proses stabilisasi. Bak ekualisasi ini berfungsi untuk mengatur debit air limbah yang akan diolah serta untuk menyeragamkan konsentrasi zat pencemarnya agar homogen dan proses pengolahan air limbah dapat berjalan dengan stabil (Kementerian Kesehatan, 2011). Selanjutnya air limbah tersebut dimasukkan ke dalam proses pengolahan dan dilakukan pengukuran kadar BOD, COD dan Amonia pada setiap perlakuan mulai jam ke-0 sampai jam ke-36.

Penurunan kadar BOD, COD dan Amonia pada perlakuan $\mathrm{R} 1$ memberikan hasil yang lebih baik disebabkan karena penggunaan media biofilter berbahan sampah plastik. Hal itu disebabkan oleh proses metabolisme yang terjadi pada lapisan biofilm yang tumbuh pada media penyangga berbahan sampah plastik selama waktu tinggal pengolahan. Polutan organik terdifusi kedalam lapisan biofilm dan diuraikan oleh mikrorganisme yang ada pada lapisan biofilm (Kementerian Kesehatan 2011). Penurunan kadar BOD, COD dan Amonia pada perlakuan R2 hanya mengandalkan mikroorganisme indegenous yang ada di air limbah (Wahyuni, 2014)

Hasil uji statistik menunjukkan penggunaan media biofilter berbahan sampah plastik memberikan pengaruh yang nyata dalam menurunkan kadar BOD dan amonia ( $\mathrm{F}$ tabel $<\mathrm{F}$ hitung), sedangkan tidak memberikan pengaruh yang nyata dalam menurunkan kadar COD (F tabel $>\mathrm{F}$ hitung). Nilai $\mathrm{F}$ tabel parameter BOD, COD dan Amonia $=6,94$ sedangkannilai $\mathrm{F}$ hitung parameter $\mathrm{BOD}=464,96$, $\mathrm{COD}=0,26$ dan Amonia = 53,45.

\subsection{Efektivitas Sistem Terhadap Penurunan Kadar BOD, COD, dan Amonia}

Tingkat efektivitas terhadap penurunan kadar BOD, COD, dan Amonia ditinjau dari dua aspek yaitu efektivitas pada proses pengolahan air limbah dan efektivitas terhadap baku mutu yang ditetapkan. Efektivitas pengolahan air limbah dalam menurunkan kadar BOD, COD dan Amonia dapat dilihat pada Tabel 1, sedangkan efektivitas baku mutu tercantum pada Tabel 2 . Kriteria efektivitas pengolahan mengacu pada Soeparman dan Suparmin (2001), yaitu : \% efektivitas $>80 \%$ (sangat efektif), $\%$ efektivitas antara $60 \%$ - 80\% (efektif), \% efektivitas antara $40 \%$ - 60\% (cukup efektif), \% efektivitas antara $20 \%$ - 40\% (kurang efektif), \% efektivitas < $20 \%$ (tidak efektif). 
Tabel 1. Efektivitas Pengolahan Sistem Dalam Menurunkan Kadar BOD, COD dan Amonia

\begin{tabular}{|c|c|c|c|c|c|}
\hline \multirow{2}{*}{ Parameter } & \multirow{2}{*}{ Perlakuan } & \multicolumn{2}{|c|}{ Kadar (mg/L) } & \multirow{2}{*}{ Persentase Penurunan Kadar (\%) } & \multirow{2}{*}{ Efektifitas Pengolahan } \\
\hline & & $\mathrm{T}_{0}$ & $\mathrm{~T}_{36}$ & & \\
\hline \multirow[t]{2}{*}{ BOD } & $\mathrm{R} 1$ & 82,37 & 11,66 & 85,84 & Sangat Efektif \\
\hline & $\mathrm{R} 2$ & 83,77 & 60,63 & 27,62 & Kurang efektif \\
\hline \multirow[t]{2}{*}{ COD } & $\mathrm{R} 1$ & 113,07 & 77,19 & 31,73 & Kurang efektif \\
\hline & $\mathrm{R} 2$ & 105,87 & 87,61 & 17,25 & Tidak efektif \\
\hline \multirow[t]{2}{*}{ Amonia } & $\mathrm{R} 1$ & 26,44 & 13,06 & 50,60 & Cukup efektif \\
\hline & R2 & 27,65 & 18,53 & 32,98 & Kurang efektif \\
\hline
\end{tabular}

Tabel 2. Efektivitas Baku Mutu Sistem Dalam Menurunkan Kadar BOD

\begin{tabular}{|c|c|c|c|c|c|c|}
\hline \multirow{2}{*}{ Parameter } & \multirow{2}{*}{ Perlakuan } & \multicolumn{2}{|c|}{ Kadar BOD (mg/L) } & \multirow{2}{*}{$\begin{array}{c}\% \text { efektivitas } \\
\text { baku mutu yang } \\
\text { ditetapkan }\end{array}$} & \multirow{2}{*}{$\begin{array}{c}\text { Capaian \% efektivitas } \\
\text { baku mutu (\%) }\end{array}$} & \multirow{2}{*}{$\begin{array}{l}\text { Efektivitas } \\
\text { baku mutu }\end{array}$} \\
\hline & & $\mathrm{T}_{0}$ & $\mathrm{~T}_{36}$ & & & \\
\hline \multirow[t]{2}{*}{ BOD } & R1 & 82,37 & 11,66 & 39,30 & 85,84 & Efektif \\
\hline & $\mathrm{R} 2$ & 83,77 & 60,63 & 31,89 & 27,62 & Tdk efektif \\
\hline \multirow[t]{2}{*}{ COD } & $\mathrm{R} 1$ & 113,07 & 77,19 & 29,25 & 31,73 & Efektif \\
\hline & $\mathrm{R} 2$ & 105,87 & 87,61 & 22,88 & 17,25 & Tdk efektif \\
\hline \multirow[t]{2}{*}{ Amonia } & $\mathrm{R} 1$ & 26,44 & 13,06 & 62,18 & 50,60 & Tdk efektif \\
\hline & $\mathrm{R} 2$ & 27,65 & 18,53 & 63,83 & 32,98 & Tdk efektif \\
\hline
\end{tabular}

Keterangan :

R1 : dengan media biofilter berbahan sampah plastik

R2 : tanpa media biofilter

Gambar 4 penurunan kadar BOD disebabkan oleh proses metabolisme yang terjadi pada sistem biofilter berbahan sampah plastik yang terdiri dari media penyangga dari bahan sampah plastik, lapisan biofilm yang melekat pada medium, lapisan air limbah dan udara yang terletak diluar. Polutan yang ada di dalam air limbah, misalnya senyawa organik (BOD, COD), amonia, fosfor dan lainnya akan terdifusi ke dalam lapisan atau film biologis yang melekat pada permukaan medium. Pada saat yang bersamaan dengan menggunakan oksigen yang terlarut di dalam air limbah, senyawa polutan tersebut akan diuraikan oleh mikroorganisme yang ada di dalam lapisan biofilm dan energi yang dihasilkan akan diubah menjadi biomasa.

Jika lapiasan mikrobiologis cukup tebal, maka pada bagian luar lapisan mikrobiologis akan berada dalam kondisi aerobik sedangkan pada bagian dalam biofilm yang melekat pada medium akan berada dalam kondisi anaerobik. Pada kondisi anaerobik akan terbentuk gas $\mathrm{H}_{2} \mathrm{~S}$, dan jika konsentrasi oksigen terlarut cukup besar, maka gas $\mathrm{H}_{2} \mathrm{~S}$ yang terbentuk tersebut akan diubah menjadi sulfat $\left(\mathrm{SO}_{4}\right)$ oleh bakteri sulfat yang ada di dalam biofilm.

Selain itu, pada zona aerobik amonium akan diubah menjadi nitrit dan nitrat dan selanjutnya pada zona anaerobik nitrat yang terbentuk mengalami proses denitrifikasi menjadi gas nitrogen. Karena di dalam sistem bioflim terjadi kondisi anaerobik dan
$\mathrm{T}_{0} \quad$ : Kadar parameter awal pada air limbah

$\mathrm{T}_{36} \quad$ : Kadar parameter setelah pengolahan selama 36 jam

aerobik pada saat yang bersamaan, maka dengan sistem tersebut proses penghilangan senyawa nitrogen menjadi lebih mudah (Kementerian Kesehatan RI, 2011).

Tabel 1 diketahui bahwa efektivitas pengolahan selama 36 jam biofilter berbahan sampah plastik sangat efektif untuk menurunkan kadar BOD dengan tingkat efektivitas mencapai $85,84 \%$. Tingkat efektivitas sebesar 85,84\% lebih tinggi bila dibandingkan dengan hasil penelitian Sugito (2013) yang hanya mampu menurunkan kadar BOD limbah cair rumah sakit sebesar $51,17 \%$. Untuk aspek efektivitas ditinjau dari aspek baku mutu menunjukan selama 36 jam pengolahan mampu menurunkan kadar BOD dibawah baku mutu yang ditetapkan (Tabel 5.2). Terjadi penurunan kadar BOD dari 82,37 mg/Lmenjadi 11,66 mg/L dengan capaian prosentase efektivitas baku mutu sebesar 85,84 \% (Tabel 2). Capaian prosentase sebesar 85,84 $\%$ menunjukan penggunaan sampah plastik sebagai media biofilter sudah mampu melampaui prosentase efektivitas baku mutu yang ditetapkan yaitu sebesar $39,30 \%$. Dari kedua aspek efektivitas yang diperoleh dapat disimpulkan bahwa pemanfaatan sampah plastik sebagai media biofilter efektif digunakan untuk menurunkan kadar BOD limbah cair rumah sakit.

Gambar 5penurunan kadar COD disebabkan oleh proses metabolisme yang terjadi pada sistem 
biofilter berbahan sampah plastik yang terdiri dari media penyangga dari bahan sampah plastik, lapisan biofilm yang melekat pada medium, lapisan air limbah dan udara yang terletak diluar. Senyawa polutan yang ada di dalam air limbah akan terdifusi kedalam lapisan atau film biologis yang melekat pada permukaan media penyangga. Pada saat yang bersamaan dengan menggunakan oksigen yang terlarut dalam air limbah senyawa polutan tersebut akan diuraikan oleh mikroorganisme yang tumbuh melekat pada permukaan media penyangga dan energi yang dihasilkan diubah menjadi biomassa (Kementerian Kesehatan RI, 2011).Persamaan umum reaksi penguraian secara aerob adalah sebagai berikut :

Bahan organik $+\mathrm{O}_{2} \stackrel{\text { Mikroba }}{\longrightarrow}$ sel baru + energi + $\mathrm{CO}_{2}+\mathrm{H}_{2} \mathrm{O}$

Tabel 1 diketahui bahwa efektivitas pengolahan selama 36 jam biofilter berbahan sampah plastik kurang efektif untuk menurunkan kadar COD dengan tingkat efektivitas mencapai 31,73\%. Aplikasi sistem biofilter untuk mengolah limbah cair rumah sakit mampu menurunkan kadar COD hingga 43,50\% (Sugito 2013) lebih tinggi dibandingkan dengan tingkat efetivitas biofilter berbahan sampah plastik. Untuk aspek efektivitas ditinjau dari segi baku mutu menunjukan selama 36 jam pengolahan mampu menurunkan kadar COD dari 113,07 mg/L menjadi 77,19 mg/L dengan capaian prosentase efektivitas baku mutu sebesar 31,73\% (Tabel 2). Capaian prosentase sebesar 31,74\% menunjukan penggunaan sampah plastik sebagai media biofilter sudah mampu melampaui prosentase efektivitas baku mutu yang ditetapkan yaitu 29,25 $\%$.

Gambar 6 penurunan kadar amonia disebabkan oleh aktivitas bakteri nitrifikasi. Di dalam proses biofiltrasi, senyawa amoniak akan diubah menjadai nitrit, kemudaian senyawa nitrit akan diubah menjadi nitrat. Mekanisme proses penguraian senyawa amoniak yang terjadi pada lapisan biofilm.Lapisan terluar media penyangga adalah lapisan tipis zona aerobik, senyawa amoniak dioksidasi dan diubah ke dalam bentuk nitrit. Sebagian senyawa nitrit ada yang diubah menjadi gas dinitrogen oksida $\left(\mathrm{N}_{2} \mathrm{O}\right)$ dan ada yang diubah menjadi nitrat. Proses yang terjadi tersebut dinamakan proses nitrifikasi (Kementerian Kesehatan, 2011).

Semakin lama, lapisan biofilm yang tumbuh pada media penyangga tersebut semakin tebal sehingga menyebabkan oksigen tidak dapat masuk ke dalam lapisan biofilm yang mengakibatkan terbentuknya zona anaerobik. Pada zona anaerobik ini, senyawa nitrat yang terbentuk diubah ke dalam bentuk nitrit yang kemudian dilepaskan menjadi gas nitrogen $\left(\mathrm{N}_{2}\right)$. Proses demikian tersebut dinamakan proses denitrifikasi. Proses nitrifikasi menurut Grady \& Lim (1980) dalam Kementerian Kesehatan RI
(2011) didefinisikan sebagai konversi nitrogen ammonium $\left(\mathrm{NH}_{4}-\mathrm{N}\right)$ menjadi nitrit $\left(\mathrm{NO}_{2}-\mathrm{N}\right)$ yang kemudian menjadi nitrat $\left(\mathrm{NO}_{3}-\mathrm{N}\right)$ yang dilakukan oleh bakteri autotropik dan heterotropik. Proses nitrifikasi ini dapat dilihat dalam dua tahap yaitu :

1. Tahap nitritasi, merupakan tahap oksidasi ion ammonium $\left(\mathrm{NH}_{4}^{+}\right)$menjadi ion nitrit $\left(\mathrm{NO}_{2}\right)$ menurut reaksi berikut:

$$
\mathrm{NH}_{4}^{+}+1 / 2 \mathrm{O}_{2}+\mathrm{OH}^{- \text {Nitrosomonas }} \mathrm{NO}_{2}^{-}+\mathrm{H}^{+}+2 \mathrm{H}_{2} \mathrm{O}+
$$

$59,4 \mathrm{Kcal}$

Reaksi ini memerlukan 3,43 g O2 untuk mengoksidasi $1 \mathrm{~g}$ nitrogen menjadi nitrit.

2. Tahap nitrasi, merupakan tahap oksidasi ion nitrit menjadi ion nitrat $\left(\mathrm{NO}_{3}^{-}\right)$yang dilaksanakan oleh bakteri Nitrobacter menurut reaksi berikut :

$\mathrm{NO}_{2}^{-}+1 / 2 \mathrm{O}_{2}$ Nitrobacter $\mathrm{NO}_{3}+18 \mathrm{Kcal}$

Reaksi ini memerlukan $1,14 \mathrm{~g}$ O2 untuk mengoksidasi $1 \mathrm{~g}$ nitrogen menjadi nitrat.

Penggunaan media biofilter berbahan sampah plastik dengan waktu pengolahan selama 36 jam belum mampu menurunkan kadar Amonia sampai dibawah baku mutu yang ditentukan. Diperlukan waktu tinggal limbah yang lebih lama untuk menurunkan kadar amonia sehingga dapat mencapai baku mutu. Menurut Wahyuni (2014) diperlukan waktu pengolahan selama 4 hari untuk menurunkan kadar amonia dengan sistem biofilter aerob dengan penambahan lumpur dari IPLT Suwung agar bisa memenuhi baku mutu yang ditentukan.

Tabel 1 diketahui bahwa efektivitas pengolahan selama 36 jam biofilter berbahan sampah plastik cukup efektif untuk menurunkan kadar Amoniadengan tingkat efektivitas mencapai 50,60 \%. Untuk aspek efektivitas ditinjau dari segi baku mutu menunjukan selama 36 jam pengolahan mampu menurunkan kadar Amonia dari $26,44 \mathrm{mg} / \mathrm{L}$ menjadi $13,06 \mathrm{mg} / \mathrm{L}$ dengan capaian prosentase efektivitas baku mutu sebesar 50,60\% (Tabel 2). Capaian prosentase sebesar 50,60 \% menunjukan penggunaan sampah plastik sebagai media biofilter belum mampu melampaui prosentase efektivitas baku mutu yang ditetapkan yaitu $62,18 \%$.

\section{SIMPULAN DAN SARAN}

\subsection{Simpulan}

Berdasarkan hasil penelitian dan pembahasan diatas dapat disimpulkan beberapa hal:

1. Penggunaan media biofilter berbahan sampah plastik memberikan pengaruh yang nyata didalam menurunkan kadar BOD dan amonia, sedangkan tidak memberikan pengaruh yang nyata didalam menurunkan kadar COD.

2. Tingkat efektivitas pengolahan sistem biofilter berbahan sampah plastik sangat efektif untuk menurunkan kadar BOD (84,85\%), cukup efektif untuk menurunkan kadar Amonia (50,60\%) dan 
kurang efektif untuk menurunkan kadar COD (31,73\%). Sedangkan tingkat efektivitas baku mutu pengolahan sistem biofilter berbahan sampah plastik efektif untuk menurunkan kadar BOD dan COD namun tidak efektif untuk menurunkan kadar Amonia selama 36 jam pengolahan.

\subsection{Saran}

1. Perlu adanya penelitian lanjutan mengenai jenisjenis sampah plastik yang lain untuk digunakan sebagai media biofilter berbahan sampah plastik

2. Untuk efektivitas pengolahan yang lebih maksimal perlu dilakukan kombinasi proses pengolahan biofilter anaerob-aerob.

\section{DAFTAR PUSTAKA}

Dewi, M. 2009. Producers Responsible for Recycling Plastic Waste. H[Cited: 2016. December, 14]. Available from: http:/www.thejakartapost.com/ news/2008/11/11/039producers-respomsible039reycling-Plastic-Waste.html.

Effendi, H. 2003. Telaah Kualitas Air Bagi Pengelolaan Sumber Daya dan Lingkungan Perairan. Yogyakarta: PT Kanisius.

Herlambang, A dan Nusa, I.S. 2001. Penurunan Kadar Zat Organik Dalam Air Sungai Dengan Biofilter Tercelup Sarang Tawon. Jakarta. Pusat TeknologiLingkungan, TPSA, BPPT.

Herlambang, A. dan R. Marsidi. 2003. Proses Denitrifikasi dengan Sistem Biofilter untuk
Pengolahan Air Limbah yang Mengandung Nitrat. Jurnal Teknologi Lingkungan. Vol 4 (1): 46-55.

Hidayat, S dan Kardena, E. 2013 "Penyisihan Senyawa Organik Limbah Air Terproduksi Pada Reaktor Batch Menggunakan Bakteri Indogenous Dan Penambahan Nutrisi" (tesis). Bandung. Institut Teknologi Bandung

Kementerian Kesehatan RI. 2011. Pedoman Teknis Instalasi Pengolahan Limbah Dengan Sistem Biofilter Anaerob Aerob pada Fasilitas Pelayanan Kesehatan. Jakarta. Kementerian Kesehatan RI, Direktorat Jenderal Bina UpayaKesehatan.

Sudarno, 2012. Perkembangan Biofilm Nitrifikasi di Fixed Bed Reactor pada Salinitas Tinggi. Jurnal Presipitasi Vol. 9 : No.1, ISSN 1907-187X

Sugito, 2013. Aplikasi Instalasi Pengolahan Air Limbah untuk Menurunkan Kandungan BOD, COD dan TSS di Rumah Sakit Bunda Surabaya. ISBN : No. 978-979-18342-0-9

Wahyuni, N.M.I. 2014. "Efektivitas Sistem Biofilter Aerob Dalam Menurunkan Kadar Amonia Pada Limbah"(tesis). Denpasar: UniversitasUdayana.

Wardhani, N.K. 2014. Sutrisno, E. dan Sumiyati, S. Penurunan Konsentrasi BOD Dan TSS Pada Limbah Cair Tahu Dengan Teknologi Kolam (Pond)-Biofilm Menggunakan Media Biofilter Jaring Ikan Dan Bioball. Semarang: Universitas Diponegoro 